\section{Ocean currents and climate}

SIR - The Leeuwin current, an anomalous eastern boundary current, flows poleward along the west coast of Australia into the prevailing southerly winds. Its existence relies on the presence of channels through the Indonesian Archipelago, allowing warm western equatorial Pacific waters to flow through to the north-west tip of Australia (see figure). It is unlike the other eastern boundary currents of the world oceans (for example, California, Peru, Canary, Benguela) in that there is neither surface equatorward flow nor coastal upwelling ${ }^{\mathrm{1}}$. These other eastern boundary currents are all part of a large-scale anticyclonic gyre driven by anticyclonic winds. Here I wish to draw an analogy between the climate effects of the Leeuwin current and the effect of the closing of the isthmus of Panama 3.2 million years ago.

The Leeuwin current is driven by a deep alongshore density gradient in the Indian Ocean $^{2-5}$. This alongshore density gradient

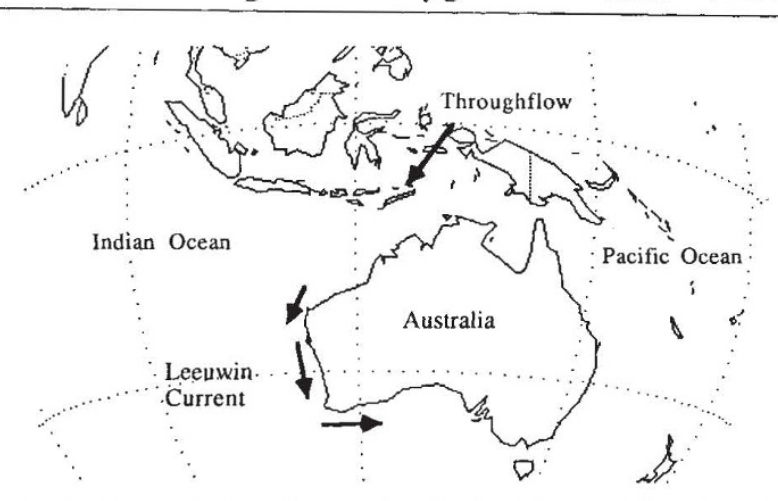

Australia and Indonesia showing the location and direction of the Leeuwin current and Indonesian throughflow.

drives a strong onshore geostrophic flow which turns and flows polewards on hitting the coast of western Australia. A passage through the Indonesian Archipelago is crucial for the existence of the deep alongshore density gradient and hence the Leeuwin current ${ }^{6}$. Warm, western equatorial Pacific waters flow through the archipelago and maintain very high steric heights off northwestern Australia. Internal Kelvin waves propagate along the coast of western Australia, radiating internal Rossby waves westward, thus tending to maintain specific volume anomaly profiles off the coast of western Australia equal to those at the equatorial end of the boundary. Polewards of about $20^{\circ} \mathrm{S}$, convective cooling occurs and the deep alongshore density gradient is set up. In a sense, therefore, the Leeuwin current can be thought of as being driven by equatorial Pacific winds which pile up warm water in the western equatorial Pacific. Furthermore, the actual magnitude of throughflow from the Pacific to Indian oceans, through the Indonesian Archipelago, has little influence on the Leeuwin current $^{6.8}$. At other eastern boundaries, the equatorial surface temperatures are much cooler and convective overturning does not occur until polewards of about $40^{\circ}$ or $50^{\circ} \mathrm{N}$ or $\mathrm{S}$ and so the circulation is dominated by local wind forcing and the flow is equatorwards.

The Leeuwin current has profound effects on the climate of western Australia. Very warm waters are advected polewards by the current and there is a large heat loss to the atmosphere poleward of $20^{\circ} \mathrm{S}$ where convective cooling occurs ${ }^{\prime}$. Perth and the rest of southwestern Australia experience a very mild and wet climate, receiving up to 50 inches of rain a year in places. This is in contrast to climates at similar latitudes on other eastern continental boundaries, for example, Baja peninsula, central Chile and Morocco, which are all very arid with less than 10 inches of rain a year.

Before about 3.2 million years ago, there was a channel through the isthmus of Panama connecting the Atlantic and Pacific oceans, much like the channel connecting the Indian and Pacific oceans observed today (Fig. 1). By analogy with the Leeuwin current, I suggest that an intense poleward flowing reverse California current existed which accelerated into the opposing winds. This current would have had a profound effect on the marine climate and environment all along the coast of California up to higher latitudes. In particular, a strong northward heat transport would occur along the western coast of North America, and a large heat loss to the atmosphere would occur poleward of about $20^{\circ} \mathrm{N}$. Along Baja and California, the climate would have been milder and wetter, similar to the climate of Perth today. In the coastal ocean, upwelling would be suppressed because the current would flow into the prevailing winds, as observed off western Australia. Thus, the nutrient abundance in the surface waters would probably be depleted, with the result that there would be a significant drop in phytoplankton and primary production.

With the closure of the isthmus of Panama, the situation would become comparable to what is observed today. The current would reverse and flow in the direction of the prevailing northerly wind. Intense upwelling would begin along the coast of North America and there would be a significant drop in the poleward heat transport in the Pacific Ocean. I also propose that a similar phenomenon may have occurred along the coast of South America where the equatorward-flowing Peru Current exists today.

ANDREW J. WEAVER

Department of Meteorology

McGill University,

Montreal, Quebec H3A 2K6,

Canada

1. Wooster, W.C. \& Reid, J.L. in The Sea Vol. 2, 253-280 (Wiley, New York, 1989)

2. McCreary, J.P., Shetye, S.R. \& Kundu, P.K. J. mar. Res. 44, 71-92 (1986)

3. Thompson, R.O.R.Y. J. mar. Res. 45, 7813-7827 (1987)

4. Weaver, A.J. \& Middleton, J.H. J. phys. Oceanogr. 19 626-648 (1989).

5. Weaver, A.J. \& Middleton, J.H. Cont. Shelf Res. 10 105-122 (1990).

6. Godfrey, J.S. \& Weaver, A.J. Prog. Oceanogr. (in the press)

7. Hanley, R.L. J. phys. Oceanogr. 1, 241-248(1971)

8. Kundu, P.K. \& McCreary, J.P. J. phys. Oceanogr. 16 2191-2198 (1986)

9. Crowley, T.J. Rev. geophys. Space Phys. 21, 828-877 (1983)

10. Crowley, T.J. in Physically-Based Modelling and Simulation of Climate and Climatic Change Part II, 883-949 (Kluwer, Dordrecht, 1988).

\section{Methane in cities}

SIR-The proposed control measures designed to reduce the climatic impact of greenhouse gases have largely been confined to cessation of release of chlorofluorocarbon gases, and less wasteful use of energy derived from the combustion of fossil fuels. We believe that improved controls on the transmission of natural gas, particularly in eastern Europe and Asia, offer a promising opportunity to slow the global build-up of methane, another significant greenhouse gas.

Because the atmospheric lifetime of methane is about 10 years ${ }^{i}$, its observed average increase of 1 per cent per year during the 1980s (ref. 2) implies a worldwide excess of only 10 per cent of methane sources over sinks. Therefore, a 10 per cent reduction in the total emissions of methane should stabilize its global concentration and eliminate any further incremental contribution of this gas to the atmospheric trapping of infrared radiation. The increase in methane concentrations has been estimated ${ }^{3}$ to have contributed about 20 per cent of the incremental infrared greenhouse forcing since 1850 .

We collected 27 whole-air samples into evacuated two-litre canisters at ground level, remote from point sources or vehicular traffic, and returned them to our laboratory for gas chromatographic analysis. Separate aliquots were analysed for methane, carbon monoxide, halocarbons and non-methane hydrocarbons from $\mathrm{C}_{\text {, }}$ to $\mathrm{C}_{5}$. Usually, we included a site $10-25$ kilometres upwind of the city centre to estimate the increase in concentration attributable to the urban area itself. Methane in air samples collected in May 1990 from four eastern European cities (Berlin, Budapest, Krakow and Prague) had substantially higher concentrations 